\title{
PERAN TAMBAHAN PELAJARAN PADA PRESTASI SISWA \\ UNTUK PELAJARAN BAHASA INGGRIS
}

\author{
Tri Budiyanti
}

$\underline{\text { dra.tribudiyati@gmail.com }}$

\begin{abstract}
Abstrak
Kurangnya jam pembelajaran/tatap muka kepada siswa menjadi kendala utama yang dihadapi pengajar mata pelajaran Bahasa Inggris. Waktu untuk mengembangkan pemahaman siswa terhadap materi menyebabkan kurangnya keterampilan untuk memahaminya menjadi suatu hal yang penting.

Berdasarkan fenomena tersebut, maka studi ini berupaya mengkaji secara empiris mengenai efektifitas tambahan jam dalam meningkatkan keterampilan Bahasa Inggris siswa. Pengumpulan dilakukan dengan mengambil subjek pada siswa kelas kelas XC dan XD tahun ajaran 2016/2017 SMK Negeri 3 Semarang. Pengujian efektifitas dilakukan dengan menggunakan pendekatan Uji independent sample t test.

Hasil studi empiris mengenai pemberian jam pelajaran tambahan pada kelompok siswa kelas XC dan XD tahun ajaran 2016/2017 menghasilkan rerata nilai akhir pada kelompok siswa yang diberi jam pelajaran tambahan lebih tinggi jika dibandingkan dengan rerata nilai akhir kelompok siswa yang tidak diberi jam pelajaran tambahan. Temuan ini menjadi bukti bahwa pemberian jam pelajaran tambahan secara efektif dapat meningkatkan nilai akhir siswa
\end{abstract}

Kata Kunci: tambahan, efektifitas

\section{PENDAHULUAN}

Hal utama yang dihadapi paran pengajar mata pelajaran Bahasa Inggris adalah kurangnya jam pembelajaran/tatap muka kepada siswa. Hal ini menunjukkan masih kurangnya waktu untuk menyampaikan materi dan terlebih pembelajaran seperti speaking dan writing, waktu untuk mengembangkan pemahaman siswa terhadap materi kurangnya keterampilan untuk memahaminya, dibuktikan kondisi awal ketika diberikan 10 soal report text tentang animal yang belum pernah dibicarakan, tingkat kebenaran jawaban mereka hanya $65 \%$. Setelah pembahasan satu teks report dan siswa diminta mengungkapkan kembali bagian dari teks yang sudah dibaca, mereka mengalami kesulitan mengungkapkannya. Dari hal yang menjadi kendala diatas maka 
selanjutnya perlu diadakannya pelajaran tambahan untuk mata pelajaran tambahan Bahasa Inggris. Apabila model penambahan jam pembelajaran ini diterapkan mulai dari materi yang sederhana sampai yang kompleks, maka diharapkan siswa dapat lebih kompeten dan dapat mengembangkan pengetahuan/serta ketrampilannya dalam berbahasa Inggris. Guru sebagai vasilitator di sekolah diuntungkan dengan pelaksanaan penambahan jam pembelajaran, karena guru dapat mempersiapkan lebih meliki banyak waktu untuk meningkatkan pengetahuan dan ketrampilan siswanya yang diharapkan dapat meningkatkan nilai akhir dan lebih kompeten.

Hal inilah yang mendasari penelitian sederhana ini, yaitu mencoba menerapkan penambahan jam pembelajaran untuk siswa agar dapat lebih bisa mengembangkan ketrampilan berbahasa inggris dan meningkatkan prestasi akademik dan non akademik siswa. Hasil yang diharapkan pada penelitian ini adalah terjadinya peningkatan prestasi akademik siswa dan semakin terampil dalam membaca teks dan berbicara bahasa Inggris.

\section{Tujuan Penelitian}

Sebagai penelitian yang berbasis tindakan kelas dan mengacu pada rumusan masalah diatas, maka penelitian ini bertujuan untuk:

1. Meningkatkan pemahaman dan keterampilan membaca report text dan speaking pada siswa kelas $\mathrm{X}$ di semester 1 SMK Semarang dengan menggunakan penambahan jam pembelajaran.

2. Meningkatkan mutu pembelajaran membaca report text dan speaking pada siswa kelas $\mathrm{X}$ di semester 1 sehingga tercipta pembelajaran yang mengaktifkan siswa dan menantang siswa untuk berpikir lebih tinggi.

\section{LANDASAN TEORI DAN HIPOTESIS}

\section{Mind Mapping}

Mind Mapping adalah bentuk pemetaan yang memetakan sesuatu berdasar hubungan yang ada, misalnya memetakan kata, gagasan, susunan, klasifikasi dan bagian bagian lainnya berdasar kekhususan.

A mind map is a diagram used to represent words, ideas, tasks, or other items linked to and arranged around a central key word or idea. Mind maps are used to 
generate, visualize, structure, and classify ideas, and as an aid to studying and organizing information, solving problems, making decisions, and writing. The elements of a given mind map are arranged intuitively according to the importance of the concepts, and are classified into groupings, branches, or areas, with the goal of representing semantic or other connections between portions of information. Mind maps may also aid recall of existing memories. (Beel, Jöran; Gipp, Bela; Stiller, JanOlaf 2009).

Mind Mapping mempresentasikan gagasan dalam bentuk garis, kotak, bone fish, tree structure, maupun bentuk bentuk lain yang yang bertujuan untuk brainstorming. Dengan mapping yang dilakukan membuat pola pikir lebih sistematis dan membantu memahami teks dengan lebih sederhana membedakan bagian dalam teks, meningkatkan word association, dan menghubungkan kata.

Mind maps are, by definition, a graphical method of taking notes. Their visual basis helps one to distinguish words or ideas, often with colors and symbols. They generally take a hierarchical or tree branch format, with ideas branching into their subsections. Mind maps allow for greater creativity when recording ideas and information, as well as allowing the note-taker to associate words with visual representations. Mind maps differ from concept maps in that mind maps focus on only one word or idea, whereas concept maps connect multiple words or ideas. (Beel, Jöran; Gipp, Bela; Stiller, Jan-Olaf 2009).

Berikut adalah guideline dalam mind mapping yang bisa digunakan dalam mempelajari report text. Penerapan dalam bacaan bisa dihubungkan dengan word class atau description of things.

\section{Keterampilan Membaca}

Keterampilan membaca yang tepat dalam penggunaan akan membantu mempermudah pemahaman teks.

Reading is a means of language acquisition, of communication, and of sharing information and ideas. Like all language, it is a complex interaction between the text and the reader which is shaped by the reader's prior knowledge, experiences, attitude, and language community which is culturally and socially situated. The reading process requires continuous practices, development, and refinement. Readers use a variety of reading strategies to assist with decoding (to translate symbols into sounds 
or visual representations of speech) and comprehension. Readers may use morpheme, semantics, syntax and context clues to identify the meaning of unknown words. Readers integrate the words they have read into their existing framework of knowledge or schema (schemata theory).

\section{Hipotesis Tindakan}

Berdasar karangka berpikir yang telah diuraikan di atas maka hipotesis tindakan adalah tambahan jam pelajaran dapat Meningkatkan Pemahaman dan Keterampilan Membaca pada pelajaran bahasa Inggis di Kelas X SMK Negeri Semarang Tahun Pelajaran 2016/2017.

\section{METODA PENELITIAN}

\section{Desain Penelitian}

Penelitian ini menggunakan metoda eksperimen lapangan (field experiment) yang menginvestigasi secara empiris dampak pemberian modul terhadap kompetensi penguasaan bahasa inggris yang ditunjukkan dari perubahan nilai siswa secara individual. Pemilihan metoda penelitian eksperimen dilakukan dalam upaya menguji hubungan kausalitas antara variabel independen dengan variabel dependen. Metoda eksperimen memiliki keunggulan yaitu kemampuannya menjawab pertanyaan tentang hubungan kausalitas antarvariabel penelitian. Desain penelitian dengan tidak menginformasikan kegiatan eksperimen kepada subjek dalam penelitian ini termasuk dalam single-blind experiment, yaitu menggunakan eksperimenter yang mengetahui tujuan penelitian namun subjek tidak mengetahui kegiatan eksperimen (Neuman, 2010).

Penelitian ini juga termasuk dalam eksperimen lapangan (field experiment). Dalam pengujian dengan eksperimen lapangan, manipulasi dan kontrol diberikan dalam kegiatan pekerjaan subjek dalam durasi waktu tertentu (Sekaran dan Bougie 2010). Pengujian hipotesis diklasifikasikan dalam pretest-posttest group design. (Shadish, Cook dan Campbell 2002).

\section{Subjek Eksperimen}


Partisipan dalam eksperimen terdiri dari siswa kelas kelas XC dan XD tahun ajaran 2016/2017. Partisipan diklasifikasikan dalam dua kondisi manipulasi yaitu diberikan penambahan jam pembelajaran dan tidak diberikan penambahan jam pelajaran bahasa inggris.

\section{Teknik Analisis Data}

Pendekatan analisis inferensial diperlukan dalam penelitian ini untuk membuktikan hipotesis yang dikembangkan dalam penelitian ini dengan menggunakan data sampel. Berpijak pada tujuan penelitian dan hipotesis penelitian maka teknik analisis inferensial yang digunakan dalam penelitian ini adalah dengan menggunakan uji komparatif.

\section{HASIL PENELITIAN}

Bagian ini merupakan pengujian statistik yang dilakukan untuk mengetahui efektifitas pemberian pemberian tambahan jam pelajaran untuk mata pelajaran bahasa inggri. Untuk kepentingan ini, pengujian dilakukan dengan menggunakan Uji Independent Sample $t$ Test dengan tahapan pengujian yang diuraikan sebagai berikut:

\section{Uji Asumsi Normalitas}

Uji asumsi normalitas dilakukan untuk mengetahui apakah data penelitian memiliki sebaran normal atau memenuhi asumsi normalitas. Pengujian normalitas data dilakukan dengan menggunakan Uji Kolmogorov Smirnov dengan kriteria sebagai berikut:

a. Jika signifikansi $>0,05$ maka data berdistribusi normal

b. Jika signifikansi $<0,05$ maka data tidak berdistribusi normal

Hasil uji Kolmogorov Smirnov pada data nilai akhir kelompok siswa yang mendapat tambahan jam pelajaran dan kelompok siswa yang tidak mendapat jam pelajaran menghasilkan nilai signifikansi sebesar 0,479. Nilai signifikansi sebesar 0,479 tersebut lebih besar dari 0,05 sehingga dapat disimpulkan bahwa data penelitian memenuhi asumsi normalitas.

2. Hasil Uji Beda pada Kelompok Siswa yang Mendapatan Jam Tambahan Pelajaran dan Kelompok Siswa yang Tidak Mendapat Jam Tambahan 
Berpijak pada hasil pengujian normalitas data dapat diketahui bahwa data penelitian memiliki distribusi normal sehingga untuk menguji ada atau tidaknya perbedaan antara kelompok siswa yang mendapat jam pelajaran tambahan dan kelompok siswa yang tidak mendapat jam pelajaran tambahan dilakukan dengan menggunakan Uji Independent Sample t Test. Pengujian dilakukan dengan tahapan berikut ini:

\section{Pengujian asumsi homogenitas variance}

Pengujian asumsi homogenitas variance dilakukan dengan menganalisis nilai signifikansi Levene's Test for Equality of Variance dengan kriteria sebagai berikut:

1) Jika nilai signifikansi $>0,05$ artinya variance data adalah homogen

2) Jika nilai signifikansi $<0,05$ artinya variance data adalah tidak homogen

Hasil signifikansi nilai Levene's Test for Equality of Variance adalah sebesar 0,357 sehingga dapat disimpulkan bahwa data memiliki variance yang homogen.

\section{a. Pengujian perbedaan}

Merujuk pada hasil signifikansi Levene's Test for Equality of Variance maka untuk menguji ada atau tidaknya perbedaan rerata nilai akhir kelompok siswa yang mendapat jam tambahan pelajaran dan rerata nilai akhir kelompok siswa yang tidak mendapat jam pelajaran tambahan dilakukan dengan menganalisis nilai signifikansi pada output Equal Variance Assumed dengan kriteria sebagai berikut:

a) Jika signifikansi $<0,05$ artinya terdapat perbedaan yang signifikan

b) Jika signifikansi $>0,05$ artinya tidak terdapat perbedaan yang signifikan

Hasil pengujian komparatif dengan Uji Independent Sample t Test menghasilkan nilai signifikansi sebesar 0,000 dimana nilai signifikansi tersebut lebih kecil dari 0,05. Hasil pengujian statistik tersebut memberikan bukti bahwa hipotesis alternatif yang berbunyi "tambahan jam pelajaran dapat Meningkatkan Pemahaman dan Keterampilan Membaca pada pelajaran bahasa Inggis di Kelas X SMK Negeri Semarang Tahun 
Pelajaran 2016/2017" dapat diterima dan dibuktikan kebenarannya secara statistik.

Pada analisis deskriptif diperoleh nilai rerata untuk kelompok siswa yang mendapat jam pelajaran tambahan sebesar 79,96 dan kelompok siswa yang tidak mendapat jam pelajaran tambahan sebesar 69,88. Artinya, jam pelajaran tambahan efektif diberikan untuk meningkatkan atau memperbaiki nilai akhir siswa untuk pelajaran bahasa inggris.

\section{PENUTUP}

\section{Kesimpulan}

Kajian empiris yang telah dilakukan pada studi ini melalui pemberian jam pelajaran tambahan pada kelompok siswa kelas XC dan XD tahun ajaran 2016/2017 telah membuktikan bahwa rerata nilai akhir pada kelompok siswa yang diberi jam pelajaran tambahan lebih tinggi jika dibandingkan dengan rerata nilai akhir kelompok siswa yang tidak diberi jam pelajaran tambahan. Temuan ini menjadi bukti bahwa pemberian jam pelajaran tambahan secara efektif dapat meningkatkan nilai akhir siswa.

\section{Saran}

Merujuk pada hasil penelitian ini maka implikasi manajerial yang diarahkan adalah agar guru dapat jam pelajaran tambahan sesuai masing-masing pelajaran yang diampu untuk diberikan kepada siswa yang dapat dilakukan sebelum kegiatan pembelajaran dimulai atau setelah kegiatan pembelajaran dimulai.

\section{DAFTAR PUSTAKA}

Permendiknas Nomor 23 Tahun 2006 tentang Standar Kompetensi Lulusan Depdiknas (2008), Kurikulum Tingkat Satuan Pendidikan, Dikmenum, Jakarta Pedoman Umum Pemilihan dan Pemanfaatan Bahan Ajar (2004) 